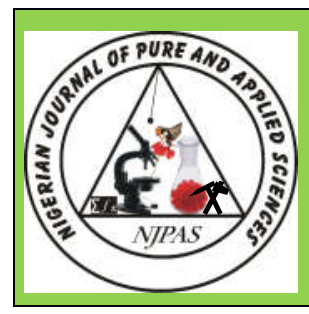

Nig. J. Pure \& Appl. Sci. Vol. 33 (Issue 1, 2020)

ISSN 0794-0378

(C) 2020 Faculty of Physical Sciences and Faculty of

Life Sciences, Univ. of Ilorin, Nigeria

www.njpas.com.ng

https://doi.org/10.48198/NJPAS/19.B29

\title{
Toxicological Evaluation of Selected Gluten-Rich Diets on Rats (Rattus norvegicus)
}

\author{
Tajudeen O. Yahaya ${ }^{1 *}$, Esther O. Oladele ${ }^{2}$, Titilola F. Salisu ${ }^{3}$, Zainab O. Ayoola ${ }^{1}$, Sofiat O. Ayodeji ${ }^{1}$
}

Page | 3547

${ }^{1}$ Department of Biology, Federal University Birnin Kebbi, Nigeria

${ }^{2}$ Biology Unit, Distance Learning Institute, University of Lagos, Nigeria

${ }^{3}$ Department of Zoology and Environmental Biology, Olabisi Onabanjo University Ago-Iwoye, Ogun State, Nigeria

\begin{abstract}
Gluten-rich foods are staple foods in many countries because they are nutritious, tasty and cosmopolitan, but lately, concerns are rife about the safety of gluten, necessitating an in-depth investigation. This study, therefore, evaluated the toxicity of two gluten-rich foods, namely wheat (Triticum aestivum) and barley (Hordeum vulgare). Eighteen (18) mixed-sex experimental rats (Rattus norvegicus) were divided into 3 groups of 6 rats each. Group 1 was made the control, while groups 2 and 3 were fed ad libitum barley and wheat diets, respectively. The rats were monitored daily for 60 days, after which blood samples were taken for hematological and liver function tests. The livers, hearts, kidneys, and ovaries of the rats were also collected for histopathological examination. The hematological parameters of the test rats, including the packed cell volume (PCV), hemoglobin (Hb), white blood cells (WBC), red blood cells (RBC), and lymphocytes (LYM) had no statistical significance $(\mathrm{p}>0.05)$, while the liver enzymes, including the alkaline phosphatase (ALP), alanine aminotransferase (ALT), total protein (TP), and albumin (ALB) were significantly elevated. There were no histopathological changes in the livers, kidneys, hearts, and ovaries of the test rats compared with the control. The rats in the wheat group completed 2 reproductive cycles, while the barley and control rats made 1 cycle each. On average, the number of offspring per birth of the control was 8 , while the barley and wheat groups had 9 and 12, respectively. The offspring survival rate of the control was $90 \%$, whereas the barley and wheat rats had 89.91 and $90.20 \%$, respectively. The results obtained showed that the gluten diets did not induce any serious side effect in the treated rats and even enhanced the health of the rats, particularly the reproductive performance. Gluten-rich foods are therefore considered safe and healthy for gluten-tolerant individuals.
\end{abstract}

Keywords: ALP, Gluten, Histopathology, PCV, Wheat.

\section{Introduction}

Gluten is a compound name given to several distinct but related proteins, grouped into a fraction formed by alcohol-soluble prolamins and another fraction formed by alcohol-insoluble glutelins (Wieser et al., 1998). Gluten can also be classified into sulfur-rich (S-rich), sulfur-poor (S- poor) and high-molecular-weight proteins (Balakireva and Zamyatnin, 2016). Gluten is the main storage protein of cereals such as wheat (Triticum aestivum), barley (Hordeum vulgare), rye (Secale cereal), and oats (Avena sativa) (Biesiekierski, 2017). Gluten cannot be denatured 
by heat and so it is used as a food additive to improve texture, flavor, and moisture retention (Kucek et al., 2015). Because of these properties, gluten is present in products such as processed meat, reconstituted seafood, candies, ice cream, Page | 3548 butter, seasonings, stuffings, marinades, and confectionery, among others (Kucek et al., 2015).

Gluten-rich diets form an important part of human daily energy intake and nutritional requirements. For example, wheat is the major cereal in some countries and is particularly increasingly popular in developing nations (Balk et al., 2019). According to FAO (2019), world cereal production may reach a record of 2722 million tons in 2019, of which wheat, maize, and barley would account for most of the rise. The acceptability of wheat is owing to its adaptability, high yield potential, and gluten content responsible for the viscoelasticity of dough processed into bread, pasta, noodles, etc. (Shewry, 2009). Wheat is also rich in amino acids, minerals, vitamins, beneficial phytochemicals, and fibre (Shewry, 2009). Barley is another highly adaptable gluten food, which ranked $4^{\text {th }}$ in the term of production behind wheat, maize, and rice (Zhou, 2010). Barley is widely consumed as food and drink because of its high nutritional content, particularly, it is a rich source of carbohydrates and beta-glucan compared to other cereals (Noaman, 2017).

However, there is an ongoing debate on the health safety of gluten-rich diets. Some studies, including Lerner et al. (2017) and Schalk et al. (2017) implicated gluten diets in hypersensitivity reactions such as celiac disease, non-celiac gluten sensitivity, and cytotoxic and inflammatory effects. On the other hand, several studies such as Neyrinck et al. (2012) and Shewry and Hey (2015) linked gluten-rich diets with some health benefits such as reduced heart disease and stroke, development of type 2 diabetes, and increased probiotic activities. This controversy has led to a significant increase in the adoption of gluten-free diets in the last few decades (Niland and Cash, 2018). Thus, an in-depth study becomes imperative to provide information towards the evaluation of health risks of gluten consumption and formulate palliative strategies if found toxic. This will go a long way to restore the confidence of consumers. This study, therefore, evaluated the toxicity of gluten-rich wheat and barley in experimental rats (Rattus norvegicus).

\section{Materials and Methods \\ Description of the Study Site}

This study was carried out in Birnin Kebbi, Kebbi State, northwestern Nigeria (Figure 1). Birnin Kebbi is the capital of Kebbi State and the headquarters of Gwandu emirate on latitude $12^{\circ} 21^{\prime} \mathrm{N}$ and longitude $4^{\circ} 36^{\prime} \mathrm{E}$ (Ajala et al., 2019). The state is bordered by Katsina and Zamfara State in the west, Sokoto State up north, Niger State in the south as well as Niger and Benin Republic in the east. The people of the state are predominantly farmers and cattle breeders and are famous in the country for cereal production.

The natural vegetation of the state is an intermix of Sudan and Guinea Savannah. However, longterm anthropogenic activities have changed the natural vegetation of the area. On average, Birnin Kebbi has a monthly and an annual rainfall of $112.21 \mathrm{~mm}$ and $787.53 \mathrm{~mm}$, respectively, with a rainy season spanning through April and October, and reaching the peak periods in June, July, August, and September (Ismail and Oke, 2012). The average temperature is $26^{0} \mathrm{C}$ but could rise above $40{ }^{\circ} \mathrm{C}$ in the peak of the hot season (MarchJuly) and fall as low as $21^{0} \mathrm{C}$ during the harmattan, between December and February (Gulma, 2013).

\section{Source of Animal Material}

Guide of care and use of animals in research and teaching of the Animal Ethics Committee of Federal University Birnin Kebbi, Nigeria, were 
followed in this study. Eighteen (18) mixed-sex rats, aged 50 days and weight $200 \pm 10 \mathrm{~g}$ were sourced from the Department of Biology, Federal University Birnin Kebbi, Nigeria in December 2018. The rats were maintained in metal cages and Page | 3549 allowed to acclimatize to the ambient conditions for 14 days before the study began. The rats had free access to water and corn feeds.

\section{Collection and Preparation of Wheat and Barley Diets}

Some quantities of wheat and barley grains were purchased from Jos and Birnin Kebbi, both in Nigeria in February 2019. The grains were identified by a curator in the Department of Botany's Herbarium, University of Lagos, Nigeria. Samples of the authenticated materials with voucher numbers LUH 8654 and LUH 8655 for $T$. aestivum and $H$. vulgare, respectively, were kept in the herbarium. The grains were ground into coarse feeds using a mortar and pestle and kept in a desiccator before use.

\section{Study Design}

The rats were divided into three (3) groups, comprising 6 rats each (3 males and 3 females). Group 1 was made the control and rats in the group were administered corn meals, while groups 2 and 3 were fed barley and wheat ad libitum, respectively. The rats were monitored daily for 60 days, after which they were sedated with chloroform in a bell-shaped glass jar and blood samples were taken for hematological and liver function tests. The rats were then sacrificed by cervical dislocation and selected internal organs, including the livers, hearts, kidneys, and ovaries, were collected for histopathological examination. All the reagents used for the experiments were sourced from chemicals of pure analytical grades.

\section{Evaluation of Reproductive Performance}

The reproductive performance of the rats was evaluated from the numbers of reproductive cycle completed by females in each group and the number of offspring born per birth. The offspring survival rate in each group was also calculated by taking the percentage of offspring that survived from the total offspring born per female.

\section{Hematological Tests}

\section{Determination of Packed Cell Volume (PCV)}

The PCV was determined by the micro-hematocrit centrifuge method described by Bull and Hay (2001). Two-third of a capillary tube was filled with each of the blood samples and one end of the tube was sealed using a Bunsen burner flame to prevent leakage, before and during spinning in the hematocrit centrifuge machine. The capillary tubes were labeled, arranged in the micro-hematocrit centrifuge machine, and centrifuged at $12000 \mathrm{rpm}$ for five minutes. The centrifugation separated the blood plasma from the red blood cells in the tubes, which was then measured using a microhematocrit reader.

\section{Determination of Hemoglobin (Hb)}

The $\mathrm{Hb}$ content was measured using the cyanmethemoglobin method as described by Hope et al. (2019). About $0.02 \mathrm{ml}$ blood was transferred into a test tube containing $5 \mathrm{ml}$ Drabkin's reagent. The solution was mixed thoroughly and allowed to stand for 10 minutes at $250{ }^{\circ} \mathrm{C}$ to allow cyanmethaemoglobin to form. The mixture was then transferred into a cuvette and read on a spectrophotometer at a wavelength of $540 \mathrm{~nm}$. The reading recorded was compared with a precalibrated chart to obtain the actual $\mathrm{Hb}$ values in $\mathrm{g} / \mathrm{dl}$.

\section{Determination of White (WBC) and Red Blood Cells (RBC)}

The WBC and RBC were estimated using the improved Neubauer hemocytometer as described by Cheekurthy (2019). The blood samples were diluted at a ratio 1:200 with ammonium oxalate and Hayem's solution and added to the hemocytometer chamber. The WBC being bigger 
was counted from the four corner squares of the chamber. To estimate the RBC, the small squares in the middle of the chamber were zoomed, and the RBC counted.

\section{Page | 3550 Determination of Lymphocytes}

The lymphocyte cells were estimated as described by Heather and Tim (2016). A drop of each blood sample was smeared on a clean glass slide and stained with a Wright-Giemsa dye, which helped to differentiate the sub-types of the WBC in the sample. The number of lymphocyte cells was then calculated using an automated blood count machine.

\section{Liver Function Tests}

\section{Determination of Alanine Amino Transferase (ALT)}

The ALT activity was estimated by colorimetric method described by Mirmiran et al. (2019). The blood samples were centrifuged at $3000 \mathrm{rpm}$ for 5 minutes to separate the blood serum. A reagent, 2, 4 dinitrophenyl hydrazine was added to the blood serum, producing pyruvate hydrazine. The ALT was measured using a Cobas Mira Plus CC Chemistry Analyzer (Switzerland), based on the colorimetric measurement of pyruvate hydrazine formed.

\section{Determination of Aspartate Amnion Transferase (AST)}

The same colorimetric method used to determine the ALT activity was also used for the AST. However, the reagent, 2, 4 dinitrophenyl hydrazine was replaced with 2, 4 nitrophenyl hydrazine, producing oxaloacetate hydrazine. The colorimetric measurement of the oxaloacetate hydrazine concentration was used to estimate the AST activity.

\section{Determination of Alkaline Phosphatase (ALP)}

The ALP activity was determined using the spectrophotometric method described by
Bergmeyer and Bernt (1974). About $0.02 \mathrm{ml}$ of the blood serum was added to $1.0 \mathrm{ml}$ diethanolamine buffer, $\mathrm{pH}$ 9.9, magnesium chloride $\left(\mathrm{MgCl}_{2}\right)$, and a substrate, p-nitrophenyl phosphate. The mixture produced was stirred, and the absorbance was taken over 1, 2 and 3 minutes using a timer at 405 $\mathrm{nm}$ in a spectrophotometer. Change in absorbance taken after 2 and 3 minutes was used to determine the final absorbance of ALP.

\section{Determination of Total Protein (TP)}

The Biuret method described by Layne (1957) was used to determine the TP. About $0.02 \mathrm{ml}$ of the blood sample was treated with an equal volume of $1 \%$ sodium hydroxide followed by a few drops of aqueous copper (II) sulfate. The mixture was stirred and incubated for 10 minutes at room temperature, after which the absorbance of the colored solution was read at $546 \mathrm{~nm}$.

\section{Determination of Albumin (ALB)}

The bichromatic digital endpoint method described by Kelly (1979) was used to determine the ALB concentrations. About $1.0 \mathrm{ml}$ of Bromcresol purple (BCP) was added to $0.02 \mathrm{ml}$ of the blood serum, producing BCP-ALB complexes. The change in the absorbance at $600 \mathrm{~nm}$ was measured with a spectrophotometer and considered the concentration of ALB in the sample.

\section{Histopathological Examination}

The tissues were prepared for histological examination based on the method of Geoffrey (2019). About $5 \mathrm{~mm}$ sample of each selected organ was fixed in $10 \%$ formal saline for 8 hours, after which they were dehydrated with ethanol. A xylene solution was used to absorb the ethanol to enable infiltration by paraffin wax heated at $55^{\circ} \mathrm{C}$. Thin sections about $6 \mu$ thick were then cut from the wax-embedded tissues and placed on clean glass slides. The slides were stained with hematoxylin and eosin and viewed with a light microscope. 


\section{Data Analysis}

The Statistical Package for Social Science (SPSS) version 20 for Windows was used for all the analyses. Comparison of data among the test and control groups was done using the student's $t$-test. $\mathrm{P}<0.05$ was considered statistically significant.
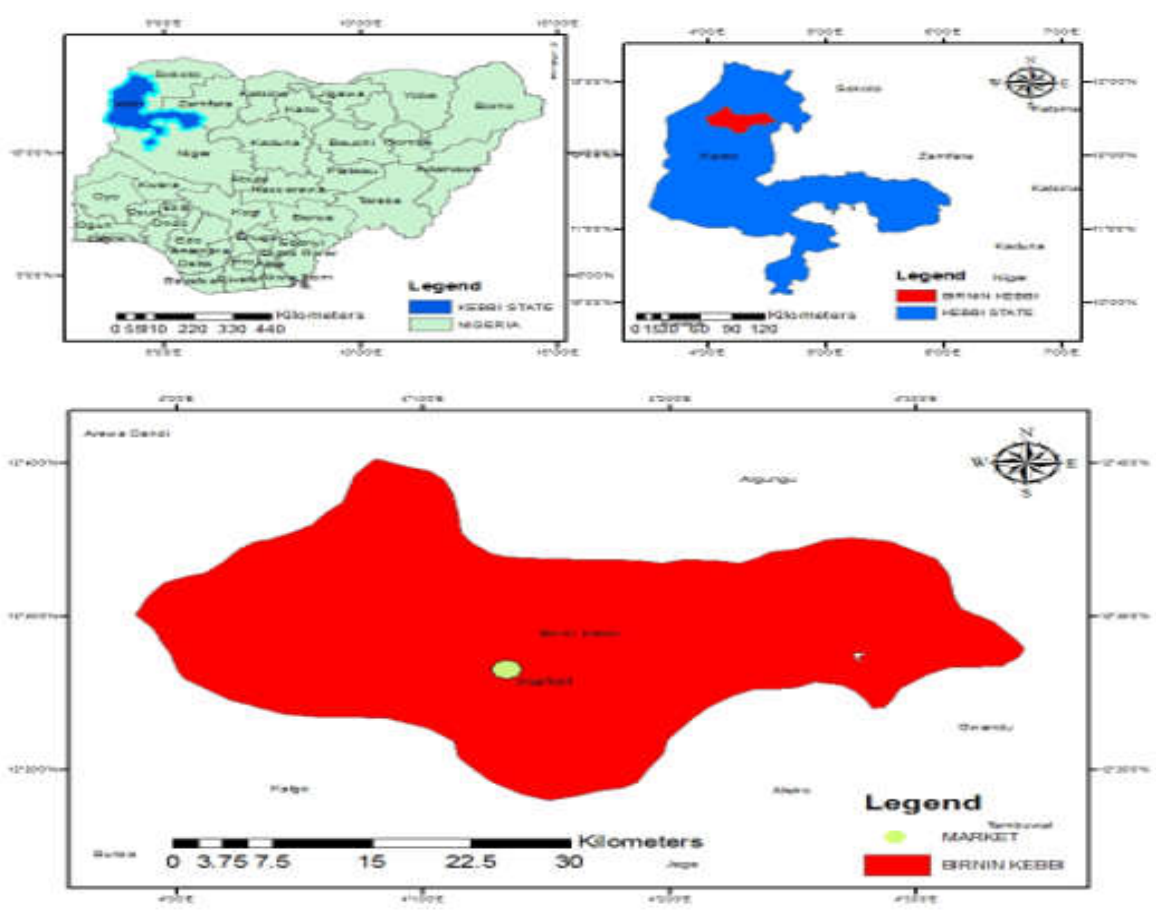

Figure 1: Maps Showing Locations of Birnin Kebbi, Nigeria

\section{Results and Discussion}

\section{Effects of Gluten-Rich Diets on Hematological Parameters}

Table 1 shows the hematological profile of the rats fed wheat and barley diets. Compared with the control, no significant differences $(p>0.05)$ were observed in the blood counts (PCV, $\mathrm{Hb}, \mathrm{WBC}$, $\mathrm{RBC}$, and LYM) of the treated groups. This suggests that gluten had no effect on blood parameters, which are major health indices of animals, including humans. Hansen et al. (2018) reported similar findings between gluten and nongluten fed individuals regarding leukocytes, lymphocytes, neutrophils, and monocytes counts. Gluten-rich whole grains have antioxidants and blood-forming vitamins and minerals such as the B vitamins, iron, copper, zinc, magnesium (Havard School of Public Health, 2019). But a study by Kooy-Winkelaar et al. (2017) indicated that gluten can interact with immune cells to produce cytokines, which predispose to cancer of the WBC. This condition, however, was observed in gluten-sensitive individuals, indicating that it may not occur in non-sensitive individuals.

\section{Effects of Gluten-Rich Diets on Liver Enzymes}

The effects of the gluten-rich diets in the liver enzymes of the treated rats are revealed in Table 2. In comparison with the control, the liver enzymes of the treated rats were altered at the end of the administration. The changes were significant $(p<0.05)$ in the ALP, ALT, TP, and ALB of the rats fed barley as well as ALP, ALT, and TP of the rats administered wheat. However, the levels of the enzymes remained within the normal ranges. This shows that gluten consumption may not cause serious biochemical problems. According to Gasteyger et al. (2008), a low-calorie diet (like the gluten-rich diets) may cause transient increases in 
liver enzymes, especially in females. Metwally and Farahat (2015) reported similar observations in the liver enzymes, including the TP, ALB, and globulin of birds fed a rice gluten diet. Hansen et al. (2018) also found no differences in the levels Page | 3548 of glucose and lipid metabolism between individuals placed on gluten diets and non-gluten diets.

\section{Effects of Gluten-Rich Diets on Reproductive Performance}

Table 3 describes the effects of wheat and barley diets on the reproductive activities of the treated rats. During the 60-day feed administration, the rats fed the wheat diet completed two reproductive cycles, while the barley and control rats made one. The wheat-fed rats also had the highest number of offspring per birth (12), followed by barley (9), and control rats (8), respectively. The offspring survival rate of the rats was highest in the wheat group $(90.20 \%)$, followed by the control rats $(90.00 \%)$, and barley rats $(89.91 \%)$, respectively. These results suggest that certain substances in gluten or gluten-containing diets can boost reproductive activities in animals, including humans. According to Neyrinck et al. (2012) and Tojo et al. (2014), gluten may act as a prebiotic, boosting the growth of beneficial gut bacteria such as the bifidobacteria, which modulates important metabolic and physiological functions. Through this mechanism, the gluten diets might boost the rats' metabolic and physiological activities related to reproductive performances. In addition, whole grains containing gluten, such as the wheat and barley contain selenium, zinc, and magnesium as well as tocols, which stimulate vitamin E activity (Brigid, 2004; Shewry and Hey, 2015). Selenium, zinc, magnesium and vitamin $\mathrm{E}$ are very important in reproductive activities. The normal offspring survival rates of the treated rats showed the health- protective role of gluten. In a study that evaluated the effects of gluten, groups with the highest intakes of gluten-containing diets had lower rates of type 2 diabetes and deaths (Mellen et al., 2008).

\section{Histopathological Effects of the Gluten-Rich Diets}

Plates 1-4 describe the histology of the rats treated with wheat and barley diets. The kidney tissues of the control and rats treated with wheat and barley diets showed normal glomeruli and tubules [Plate $1(\mathrm{a}, \mathrm{b}$, and $\mathrm{c})]$, while normal cardiac myocytes were found in the heart tissues of the control and rats administered wheat and barley [Plate $2(\mathrm{a}, \mathrm{b}$, and c)]. The liver tissues of the control rats showed normal hepatocytes, which were also observed in the livers of the rats fed wheat and barley [Plate $3(\mathrm{a}, \mathrm{b}$, and c) ]. Plate $4(\mathrm{a}, \mathrm{b}$, and c) showed that the ovaries of the control and barley rats had normal ovarian follicles, while normal papillary luminal architecture was observed in the rats fed wheat. These results showed that gluten did not induce any histopathological effects. Lebwohl et al. (2017) reported similar findings in which long-term consumption of gluten did not induce any heart injury. Viljamaa et al. (2005) and Guidetti et al. (2001) also reported no increased risk of autoimmune diseases following gluten diets consumption. In a study that monitored the effects of a low-gluten diet on immune and inflammatory responses, no changes were seen in the concentrations of systemic inflammatory markers in serum (Hansen et al., 2018). According to Kumar (2011) and Rosell (2012), gluten diets contain a considerable amount of carbohydrates, protein, calcium, iron, zinc, magnesium, phosphorus, potassium, phytochemicals, and vitamins $\mathrm{B}$ and $\mathrm{E}$, all which protect and repair tissues. 
Table 1: Hematological Parameters of Rats Feed with Wheat and Barley

\begin{tabular}{lccc}
\hline \multicolumn{1}{c}{ Parameters } & \multicolumn{1}{c}{ Control } & \multicolumn{1}{c}{ Wheat } & Barley \\
\hline PCV $\left(\mathrm{L} \mathrm{L} \mathrm{L}^{-1}\right)$ & $0.28 \pm 0.05^{\mathrm{a}}$ & $0.29 \pm 0.06^{\mathrm{a}}$ & $0.29 \pm 0.05^{\mathrm{a}}$ \\
$\mathbf{H b}\left(\mathrm{g} \mathrm{dL}^{-1}\right)$ & $10.80 \pm 1.60^{\mathrm{a}}$ & $10.90 \pm 2.11^{\mathrm{a}}$ & $11.33 \pm 2.90^{\mathrm{a}}$ \\
$\mathbf{W B C}\left(\mathrm{mc} \mathrm{mm}^{-3}\right)$ & $4210 \pm 157^{\mathrm{a}}$ & $4157 \pm 205^{\mathrm{a}}$ & $4001 \pm 200^{\mathrm{a}}$ \\
$\mathbf{R B C}\left(\mathrm{mc} \mathrm{mm}^{-3}\right)$ & $4.99 \pm 1.10^{\mathrm{a}}$ & $5.10 \pm 1.88^{\mathrm{a}}$ & $5.19 \pm 1.50^{\mathrm{a}}$ \\
$\mathbf{L Y M}\left(\mathrm{c} \mu \mathrm{L}^{-1}\right)$ & $83.00 \pm 10^{\mathrm{a}}$ & $81.00 \pm 8.0^{\mathrm{a}}$ & $83.00 \pm 9.0^{\mathrm{a}}$ \\
\hline
\end{tabular}

Values were expressed as mean $\pm \mathrm{SD}(\mathrm{n}=6)$; values along the row with the same superscript as the control are not statistically different at $\mathrm{p}<0.05$ (student's $t$-test); $\mathrm{PVC}=$ packed cell volume; $\mathrm{Hb}=$ hemoglobin; $\mathrm{WBC}=$ white blood cells; $\mathrm{LYM}=$ lymphocytes.

Table 2: Levels of the Liver Enzymes of Rats Treated with Wheat and Barley Diets

\begin{tabular}{llllll}
\hline Diet & ALP $\left(\mathbf{U ~ L}^{-1}\right)$ & AST $\left(\mathbf{U ~ L}^{-1}\right)$ & ALT $\left(\mathbf{U ~ L ~ L}^{-1}\right)$ & TP $\left(\mathbf{g ~ d L}^{-1}\right)$ & ALB $\left(\mathbf{g ~ d L}^{-1}\right)$ \\
\hline Control & $21.00 \pm 1.00$ & $11.67 \pm 1.53$ & $13.00 \pm 1.00$ & $7.00 \pm 1.00$ & $4.07 \pm 1.53$ \\
Barley & $17.67^{*} \pm 2.52$ & $12.67 \pm 2.52$ & $07.67^{*} \pm 3.06$ & $9.43^{*} \pm 2.41$ & $3.73^{*} \pm 1.15$ \\
Wheat & $15.33^{*} \pm 2.52$ & $11.67 \pm 1.53$ & $07.33^{*} \pm 1.53$ & $7.80^{*} \pm 1.72$ & $4.06 \pm 1.53$
\end{tabular}

Values were expressed as Mean $\pm \mathrm{SD}(\mathrm{n}=6)$; values with an asterisk $\left(^{*}\right)$ on the same column are statistically different from control at $\mathrm{p}<0.05$ (Student's $t$-test). ALP $=$ Alkaline Phosphatase; AST $=$ Aspartate Amnion Transferase; $\mathrm{ALT}=$ Alanine Amino Transferase; $\mathrm{TP}=$ Total Protein; $\mathrm{ALB}=$ Albumin.

Table 3: Reproductive Performance of the Rats Fed Wheat and Barley Diets

\begin{tabular}{lccc}
\hline Diet & $\begin{array}{l}\text { No of Reproductive Cycles in Offspring Per Birth } \\
\text { 60 Days }\end{array}$ & $\begin{array}{l}\text { Offspring Survival } \\
\text { Rate (\%) }\end{array}$ \\
\hline Control & 1 & 8 & 90.00 \\
Barley & 1 & 9 & 89.91 \\
Wheat & 2 & 12 & 90.20 \\
\hline
\end{tabular}




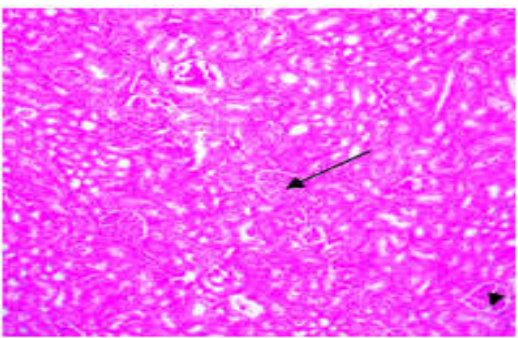

[a]

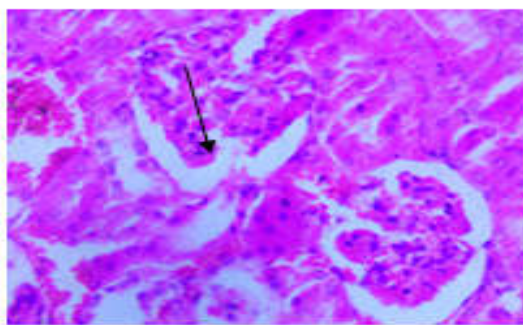

[b]

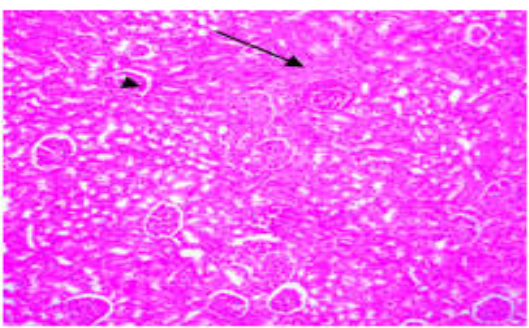

[c]

$\mathbf{a}=$ control rats showing normal glomeruli (long arrow) and tubules (short arrow); $\mathbf{b}=$ wheat-fed rats showing normal glomeruli; $\mathbf{c}=$ barley-fed rats showing normal glomeruli (long arrow) and tubules (short arrow)

Plate 1: Photomicrograph of the Kidney Sections of the Control and Treated Rats (x 100)

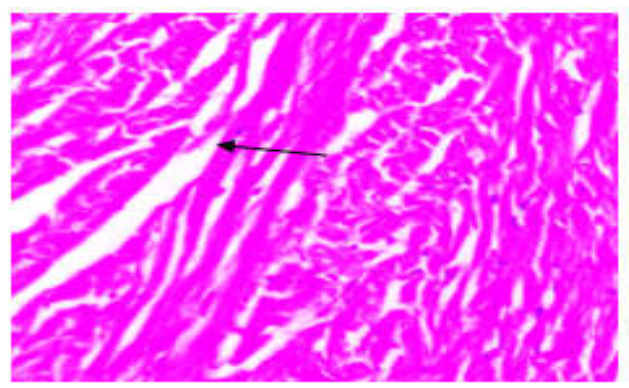

[a]

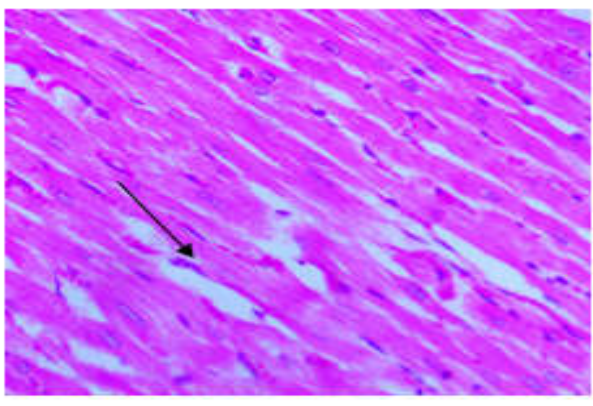

[b]

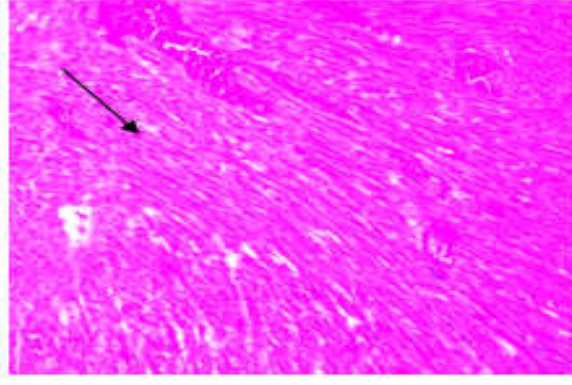

[c]

$\mathbf{a}=$ control rats showing normal cardiac myocytes; $\mathbf{b}=$ wheat-fed rats showing normal cardiac myocytes; $\mathbf{c}=$ barley-fed rats showing normal cardiac myocytes

Plate 2: Photomicrograph of the Heart Sections of the Control and Treated Rats (x 100) 


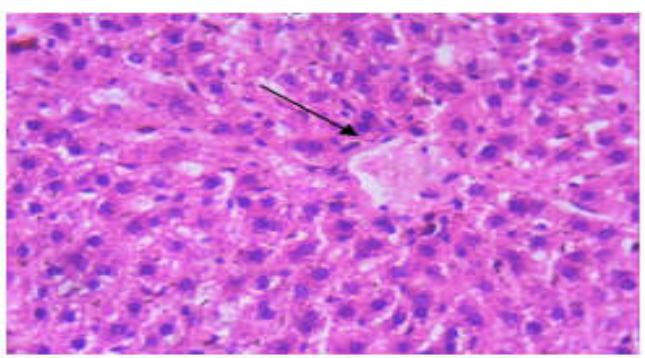

[a]

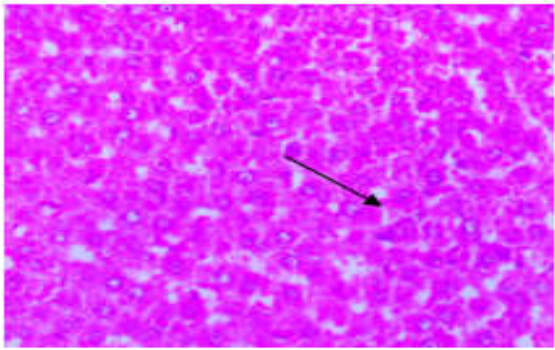

[b]

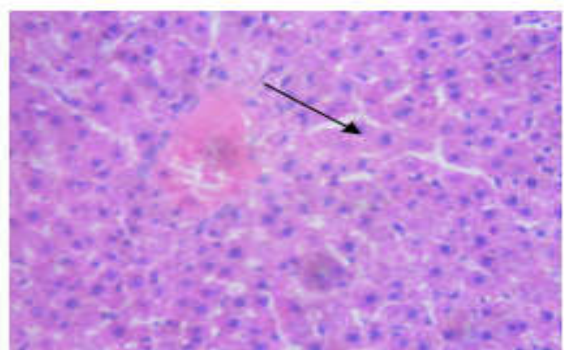

[c]

$\mathrm{a}=$ control rats showing normal hepatocytes; $\mathrm{b}=$ wheat-fed rats showing normal hepatocytes $\mathrm{c}=$ barley-fed rats showing normal hepatocytes

\section{Plate 3: Photomicrograph of the Liver Sections of the Control and Treated Rats (x 100)}

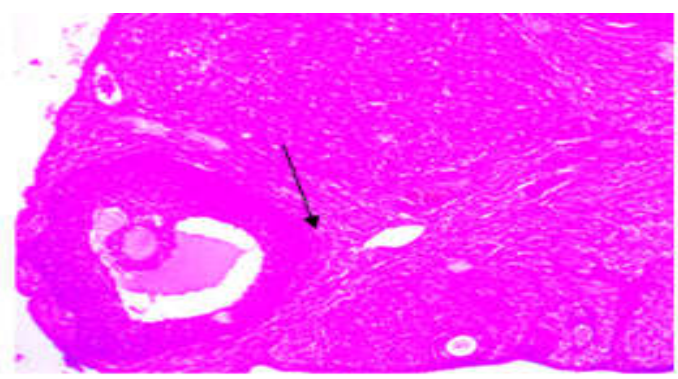

[a]

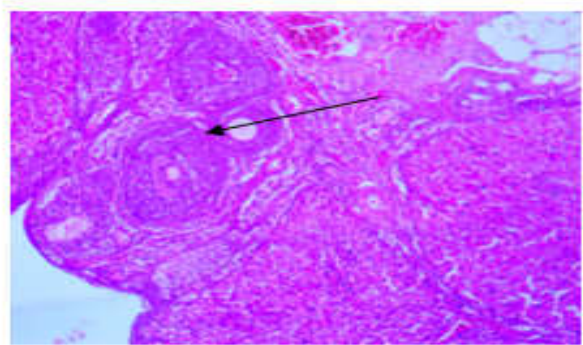

[b]

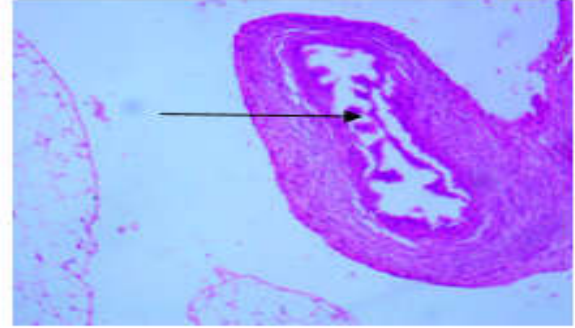

[c]

$\mathbf{a}=$ control rats showing normal ovarian follicles; $\mathbf{b}=$ barley-fed rats showing normal ovarian follicles $\mathbf{c}=$ wheat-fed rats showing normal papillary luminal architecture

Plate 4: Photomicrograph of the Ovary Sections of the Control and Treated rats (x 100) 


\section{Conclusion}

The results obtained showed that the gluten-rich diets, wheat and barley did not adversely affect the histology as well as hematological and Page | 3552 biochemical parameters of the treated rats at the evaluated days of study. This suggests that consumption of gluten-rich diets may not elicit harmful effects in biological systems. In addition, the study established a link between intakes of gluten-rich diets and enhanced reproductive performances. This was demonstrated by the increased number of the reproductive cycle completed by the wheat-fed rats and offspring per birth of both the wheatand barley-fed rats. The protective role of gluten diets was also demonstrated in the normal offspring survival rates of the treated rats compared with the control. Collectively, the results showed that gluten-rich diets contain some health-boosting phyto- chemicals, vitamins, and minerals whose absence may initiate diseases in the body. This further suggests that the reported adverse effects of gluten consumption in some studies could be that the individuals were allergic or intolerant to gluten.

\section{Conflict of Interest}

The authors have no interest to declare

\section{References}

Ajala, A., Muhammad, A., Yakubu, A., Adamu, M. and Busari, Y. (2019). Correlation Study on Growth and Yield Components of Rice (Oryza sativa L.) Varieties Grown under Integrated Weed Management in Sudan Savanna of Nigeria. Journal of Agriculture and Ecology Research International, 19(1), 1-6.

https://doi.org/10.9734/jaeri/2019/v19i1300 $\underline{75}$.

Balakireva, A. V. and Zamyatnin, A. A. (2016). Properties of Gluten Intolerance:
Gluten Structure, Evolution, Pathogenicity and Detoxification Capabilities. Nutrients, 8 (10): 644. doi:10.3390/nu8100644

Balk, J., Connorton, J. M., Wan, Y., Lovegrove, A, Moore, K. L, Uauy, C, Sharp, P. A. and Shewry, P. R. (2019). Improving wheat as a source of iron and zinc for global nutrition. Nutrition Bulletin, 44 (1): 22-31

Bergneyer, H. U. and Bernt, E. (1974). In: method of enzymatic analysis; Berdnery, H.U. $2^{\text {nd }}$ ed., Academic press, New York, NY, 2:574-579.

Biesiekierski, J. R. (2017). What is gluten? Journal of Gastroenterology and Hepatology, 32 (S1). https://doi.org/10.1111/jgh.13703

Brigid, M. (2004). Nutritional aspects of cereals. Nutrition Bulletin, 29 (2): 111-142. https://doi.org/10.1111/j.14673010.2004.00418.x

Bull, B. S. and Hay, L. K. (2001). Is the pack cell volume (PCV) reliable? Laboratory Haematology, 7:191-196.

Cheekurthy, A. J. (2019). Prevalence of Anaemia and Abnormality in Absolute Blood Count in

Type 2 Diabetes Mellitus Patients. EC Diabetes and Metabolic Research, 3; 1: 0609.

Dasharatham, P. and Reddy, V. (2018). A Study of etiological and Clinical Profile of Patients with Severe Anemia in a Tertiary Care Hospital. International Journal of Advanced Medicine, 5 (6): 1422-1427.

Food and Agricultural Organization (2019). World Food Situation: FAO Cereal Supply and Demand Brief. Available online@ http://www.fao.org/worldfoodsituation/csdb len/

Gasteyger, C., Larsen, T. M., Vercruysse, F. and Astrup, A. (2008). Effect of a dietaryinduced weight loss on liver enzymes in obese subjects, The American Journal of 
Clinical Nutrition, 87 (5): 1141-1147. https://doi.org/10.1093/ajen/87.5.1141

Geoffrey, O. R. (2018). An Introduction to Specimen Processing. Available at https://www.leicabiosystems.com/knowledg e-pathway/an-introduction-to-specimenprocessing/

Guidetti, C. S., Solerio, E., Scaglione N., Aimo G. and Mengozzi, G. (2011). Duration of gluten exposure in adult coeliac disease does not correlate with the risk for autoimmune disorders. Gut, 49:502-505. doi: 10.1136/gut.49.4.502.

Gulma, L. U. (2013). An Analysis of Temporal Rainfall Variability in Argungu Area over the Last Half Climatic Year (1995-2012): Implication on Rain fed Crop Production. Academic Journal of Inter disciplinary Studies, 2 (12):117-122.

Doi:10.5901/ajis.2013.v2n12p117

Hansen, L. B. S., Roager, H. M., Søndertoft, N. B., Gobel, R. K., Kristensen, M., VallèsColomer, M. and Vieira-Silva, S. (2018). A low-gluten diet induces changes in the Intestinal microbiome of healthy Danish adults. Nature Communication, 9: article no 4630. https://doi.org/10.1038/s41467-01807019-x

Harvard School of Public Health (2019). The Nutrition Source. Available online at https://www.hsph.harvard.edu/nutritionsour ce/what-should-you-eat/whole-grains/

Heather, R. and Tim, J. (2016). Blood differential test: what is a blood differential test? Available online at https://www.healthline.com/health/blooddifferential\#1

Hope, O., Ifeanyi, O. E., Braxton, A. Q. (2019). Investigation of some Haematological Parameters in Pregnant Women with Gestational Diabetes at Federal Medical Center, Owerri, Imo State, Nigeria. Annals of Clinical Laboratory Research, 7 (2):305309.
Ismail, A. and Oke, I. A. (2012). Trend analysis of precipitation in BirninKebbi, Nigeria. International Research Journal of Agricultural Science and Soil Science, 2 (7):286- 297

Kelly, A., McKenna, J. P., McLelland, A., Percy, R. A. and Spooner, R. J (1979). A Bichromatic Method for Total Bilirubin with a CentrifiChem 400. Clinical Chemistry, 25 (8): 1482-1484.

https://pdfs.semanticscholar.org/ded8/338f5 cd9cd1673e29f1abd49a5a8c9fea24d.pdf

Kooy-Winkelaar, Y. M. C, Bouwer, D., Janssen, G. M. C, Thompson, A., Brugman, M. H., Schmitz, F., de Ru, A. H., van Gils, T., Bouma, G., van Rood, J. J., van Veelen, P. A., Mearin, M. L., Mulder, C. J., Koning, F., and van Bergen, J. (2017). CD4 T-cell cytokines synergize to induce proliferation of malignant and nonmalignant innate intraepithelial lymphocytes. PNAS. https://doi.org/10.1073/pnas.1620036114

Kucek, L. K., Veenstra, L. D., Amnuaycheewa, P. and Sorrells, M. E. (2015). A grounded guide to gluten: how modern genotypes and processing impact wheat sensitivity. Comprehensive Review in Food Science and Safety, 14: 285-302. https://doi.org/10.1111/1541-4337.12129

Kumar, P., Yadava, R. K., Gollen, B., Kumar, S., Verma, R. K. and Yadav, S. (2011). Nutritional Contents and Medicinal Properties of Wheat: A Review. Life Sciences and Medicine Research, 22: 1-10. http://astonjournals.com/manuscripts/Vol20 11/LSMR-22_Vol2011.pdf

Layne, E. (1957). Spectrophotometric and Turbidimetric Methods for Measuring Proteins. Methods in Enzymology, 10:447455.

Lebwohl, B., Cao, Y., Zong, G., Hu, F. B, Green, P. H. R, Neugut, A. and Rimm, E. B. (2017). Long term gluten consumption in adults without celiac disease and risk of 
coronary heart disease: prospective cohort study. BMJ, 357:j1892.

doi: $10.1136 /$ bmj.j1892.

Lerner, A., Shoenfeld, Y. and Matthias, T. (2017). Adverse effects of gluten ingestion and advantages of gluten withdrawal in non-celiac autoimmune disease. Nutrition, 75

(12):1046-1058.

doi:10.1093/nutrit/nux054.

Mellen, P. B, Walsh, T. F. and Herrington, D. M. (2008). Whole grain intake and cardiovascular disease: a meta-analysis. Nutrition, Metabolism and Cardiovascular Disease, $\quad 18: 283-90 . \quad$ DOI: 10.1016/j.numecd.2006.12.008

Metwally, A. and Farahat, M. (2015). Nutritive value and feeding of rice gluten meal in broiler chickens. Research Opinion in Animal and Veterinary Sciences, 5 (11): 443-451.

Mirmiran, P., Gaeini, Z., Bahadoran, Z, Azizi, F. (2019. Elevated serum levels of aminotransferases in relation to unhealthy foods intake: Tehran lipid and glucose study. BMC Endocrine Disorders, 19: 100. https://doi.org/10.1186/s12902-019-0437-5

Neyrinck, A. M., Van Hée, V. F, Piront, N., De Backer, F., Toussaint, O., Cani, P. D, Delzenne, N. M. (2012). Wheat-derived arabinoxylan oligosaccharides with prebiotic Effect increase satietogenic gluten peptides and reduce metabolic endotoxemia in diet-induced obese mice. Nutrition and Diabetes, 2 (1): e28. doi: 10.1038/nutd.2011.24.

Niland, B. and Cash, B. D. (2018). Health Benefits and Adverse Effects of a GlutenFree Diet in Non-Celiac Disease Patients. Gastroenterology and hepatology, 14(2):82-91.

Noaman, M. W. (2017). New Utilization of Barley as Human Healthy Food. Journal of Plant Breeding and Agriculture, 1(1):1-2.
Rosell, C. M. (2012). Breadmaking. 2nd ed. Woodhead Publishing; Cambridge, UK: Pp 687-710.

Schalk, K., Lexhaller, B., Koehler, P. and Scherf, K. A. (2017). Isolation and characterization of gluten protein types from wheat, rye, barley and oats for use as reference materials. PloS one, 12 (2): e0172819. doi:10.1371/journal.pone.0172819

Shewry, P. R. (2009). Wheat. Journal of Experimental Botany, 60: 1537-1553.

Shewry, P. R. and Hey, S. J. (2015). The contribution of wheat to human diet and health. Food and Energy Security, 4 (3). https://doi.org/10.1002/fes3.64

Tojo, R., Suárez, A., Clemente, M. G., de los Reyes-Gavilán, C. G., Margolles, A., Gueimonde, M. and Ruas-Madiedo, P. (2014). Intestinal microbiota in health and disease: role of bifidobacteria in gut homeostasis. World journal of gastroenterology, 20 (41): 15163- 15176. doi:10.3748/wjg.v20.i41.15163

Viljamaa, M., Kaukinen, K., Huhtala, H., Kyrönpalo, S., Rasmussen, M. and Collin P. (2005). Coeliac disease, autoimmune diseases and gluten exposure. Scandinavian Journal of Gastroenterology, 40:437-443. doi: 10.1080/00365520510012181

Wieser, H., Antes, S. and Seilmeier, W. (1998). Quantitative determination of gluten protein types in wheat flour by reversed phase high performance liquid chromatography. Cereal Chemistry, 75 (5): 644-650. https://doi.org/10.1094/CCHEM.1998.75.5. 644.

Zhou, M. (2010). Barley Production and Consumption. In book: Genetics and Improvement of Barley Malt Quality, Chapter 1.DOI: 10.1007/978-3-642-012792 - 1 . 